tissue. Hence the transverse striation plainly seen after death in the adhesions. In harmony with this explanation, those parts are usually the seat of the greatest pleural thickening where falling-in of the chest meets with the greatest difficulty. In the ordinary apex-excavations the thickest pad of fibrous tissue occurs in the axillary region, coinciding with the greatest convexity of the ribs. Fibrous tissue is not the only substance employed by nature as a stop-gap. Very frequently fat is produced in appreciable quautities in the retro-pleural tissue. This I have often otserved over the site of contracting cavities. (See Fig. 7.) The favourite situation is the internal surface of the ribs, as originally pointed out to me by Dr. R. E. Thompson. A contracted lung removed from the chest in connexion with the adherent pleura usually presents the appearance of deep parallel grooves, which alternate with prominent ridges, suggesting an analogy with the costal in dentations of a pneumonic lung, but in reality presenting the exact counterpart of this condition. In pneumonia the groove corresponds to the bed of a rib; in the contracted lung the position of the rib is marked in relief, and that of the intercostal space by a depression. The retraction of the fibrosed lung readily draws inwards the soft parts; but a similar in-bending of the rib is clearly impossible: in this situation the visceral layer of the pleura retreats from the perio-teum, and the interval between pleura and bone is filled by fat.

\section{ON THE ADVISABILITY OF ENUCLEATING THE AXILLARY GLANDS IN CASES OF} REMOVAL OF SCIRRHOUS MAMM ${ }^{1}{ }^{1}$

By A. PEARCE GOULD, M.S., ASSISTANT-SURGEON TO THE WESTMINSTER HOSPITAL

MY object in this paper is to urge that in all cases where the mamma is amputated for cancerous disease the surgeon should remove also the axillary lymphatic glands. It is a cardinal rule in surgery, and very rightly so, that excisions of cancerous growths should only be undertaken when the surgeon can remove the whole of the diseased structures, and it is my desire to show that that rule applies to the case in point. Let me state at once that in all that follows I am limiting myself strictly to the one point named in the title of this paper, and that I assume that the cases of cancer of the breast removed are in other respects suitable for that operation, and that they satisfy the rule above quoted. For my purpose it will be convenient to divide the cases of cancer of the breast suitable for operation into: (1) Those complicated with evident enlargement of axillary lymphatic glands, and (2) those not so complicated.

1. Is it right is it wrong to operate for cancer of the breast where the lymphatic glands in the axilla are obviously enlarged from secondary cancerous growth? The answer to this question depends upon the answers to two others: Can we safely remove cancerous glands from the axilla? and, Does the cancerous infection stop at the lymphatic glands fir so long a period that there is time for tho e ylauds to become distinctly enlarged before the malignant disease has been carried to, and grown in, internal organs? The practicability of the operation must of necessity vary with individual cases. Where the glands are still freely movable it is easy to enucleate them; where they are firmly fixed down to the chest wall, it is imposible to remove the whole of the diseased structures without serious risk, or even the certainty, of fatal injury to the thoracic cavity. Between these two extremes there are several grades of severity. But if we look at the dangers and difficulties of the operation, we shall best arrive at the true answer. By drawing the arm well away from the side, and prolonging the mammary incision outwards, the axilla is easily expused. The $d$ ingers are the primary ones of wound of the large bloodvesstls and nerves, and wound of the pleural cavitv. As the hloodvessels and nerves are very constant in their position the suryeon always knows where his danyer lies, and even when the growths are adherent to these parts he can often, by slow and very careful dissection, separate

\footnotetext{
1 Read before the Medical Society of London, March 27 th.
}

them without wounding either vessels or nerves. The intercosto-humeral nerve, which crosses the axillary space, is most of all exposed to injury, and must be very generally cut or torn across. One common way of avoiding the danger of hæmorrhage is to separate the mass to be removed, except at the end next the vessels, and then to throw a strong ligature around this pedicle, and cut the mass away on the distal side of the ligature. This is only a "surgical makeshift." It is far better, by care and patience, especially patience, to separate the growth all round. If vessels of any size are fousd entering it, ligature them separately. The disadvantages of the makeshift plan are, that the vessels in the pedicle are not so securely tied; nerves as well a i vessels may be included in it; and there is no certainty that the surgeon has removed all the diseased tissues.

The secondary dangers of the operation are suppuration in the axilla and thrombosis of axillary vein. In my own experience these accidents have not occurred, and I have found these wounds in the axilla heal very well, if $I$ took three precautions: to put a drain up into the cavity, to apply suitable padding to keep the walls of the cavity in apposition, and to keep the arm fixed to the side.

I may briefly relate one case of removal of cancerous axillary glands under my own care.

On Aug. 30th, 1880, I operated at Westminster Hospital on C. C- - aged fifty-one, who had a scirrhous tumour in the right breast as large as an orange, and enlarged glands in the axilla the size of an apricot. After removing the mamma and a large portion of the skin over it in the usual manner, I carried the incision up and out into the axilla, and first of all carefully detached the cancerous glands from the side of the chest; it was then found that they were not only adherent to but growing completely round the axillary vein and some of the nerves of the brachial plexus. I cut down through the mass on to the coat of the vein, and was then able to peel the glands off the vein and nerves, leaving them uninjured. Unfortunately, before doing this I had put a ligature on the vein, as it at first seemed impossible to finish the operation without wounding it; this precaurion, however, proved to have been unnecessary. The external mam. mary and one small superficial artery were the only vessels ligatured. The axillary wound healed at once, except a narrow track occasioned by the silk ligature round the vein. I saw this womar last year. She was then well. I need not quote other cases I have had; this was perhaps the worst of all. The only time I had any hæmorrhage was once when I wounded the subscapular vein close to its junction with the axillary ; it was easily secured with a ligature, and caused no further trouble.

As to the second question, I think all will agree that there is often an interval of many months between the discovery of cancerous infection of the axillary glands and the appearance of signs of cancerous disease iu the internal organs. But the facts I would adduce in support of this statement are these :- (1) That systemic secondary cancer without antecedent glaudular infection is very $\mathrm{r}$ *re, being met with in only about 13 per cent. of such cares. (2) That, in cases of death from cancer of the breast, infection of the glands is met with far more frequently than infecti in of any otherorgan. Thus, in 128 autopsies, the glands were found cancerous in 115 cases, and the liver, which stands next in order of frequency, was infected only fifty-five times; the lung twenty-eight times; and then comes a great fall to units. What is the meaning of these facts but that the path of the cancerous poison from the breast is throngh the axillary lymphatic glands, and that the poison is delaved in its yassave through these glands, often for a long period? Hf nce, on pathological grounds, this operation is justifiable. Practically, it is a safe procedure, not adding greatly to the risk of the simpler operation, and clinically it is successful; for, out of ninety-three cases tabulated by Oldekop and Wini warter, in which this was done, the mean subsequent life was $39 \cdot 3$ months. And Gross states that in as many as one-third of the cases submitted to a complete operation-i.e., clearing out the axilla-no recurrence was observed up to so long as six years afterwards.

2. Is it right, or is it wrong, when operuting for cancer of the breast, in which no lymphatic enlargement can be detected, to remove the axillary lymphatic glands? Practically this is a very simple procedure. A very small-extension of the wound allows the finger to be passed iuto the axil!ary space, ands with it the glands can be teadily euurleated, without danger to nerves, vessels, or pleura. Or, better, a careful dissection of the axilla can be made. The small twigs of alar thoracic vessels, which are necessarily divided, are not 
large enough to require any treatment. A small drain should then be put in the axilla and the wound treated as already mentioued. Such a procedure hardly, if at all, adds to the danger of the original operatio.. But is it of any advantage? I believe it is, for I believe that in the very earliest stage of lymphatic infection it is impossible to detect any enlargement of the glands by the ordinary examination through the skin. Such a case oceurred to me quite lately. A patient was brought to me by my friend, Dr. Shaw of Enfield, with a scirrhous cancer in the right mamma. Neither I nor Dr. Shaw nor Mr. Macnamara, who afterwards saw the case with me, could detect any lymphatic enlargement. But after excising the mamma $I$, as a matter of routine, proceeded to remove the axillary glands, and then I found that two of them were evidently already cancerous, in one the focus of disease being about the size of a shot, in the other of a pea. My friend, Dr. Heneage Gibbes, has prepared some microscopical sections of those glands, which prove the cancerous nature of the growths. Now here was convincing proof that had I simply contented myself with excising the mamma, I should almost directly have found a recurrence in the axilla, and this one case was sufficient to convince me that cancer may exist in axillary lymphatic glands which cannot be detected by the ordinary methods of examination. The only other explanation is, that had I used proper care and skill I should have detected these minute growths. To which I can only reply, that I examined the axilla repeatedly and with care, and that if I made an oversight, so did Dr. Shaw and Mr. Macnamara, and therefore it is an oversight that may be expected to be made. Further, recurrence in the axillary glands, apart from local recurrence, is not uncommon after removal of the mamma alone. And recurrence in the axilla is far more frequent after removal of the breast alone than when the glands are simultaneously removed. The axillary glands are not of functional importance at the age when cancer occurs.

In conclusion I would formulate my argument thus :-

1. Partial excision of a cancer should never be performed.

2. Where breast and axillary glands are cancerous the breast alone should never be excised.

3 . That in very many cases of cancerous axillary glands excision can be performed with only slight additional danger, and with great benefit to the patient.

4. That the cases where such excision is not practicable are those in which the growth has spread to the chest walls. Pressure upon, or even adhesion to, the main bloodvessels and nerves of the axilla is not an insuperable bar to the operation, if sufficient care be taken.

5 . That when no enlargement of axillary glands is to be made out, those glands may yet be infected with cancer, and that, therefore-

6. Even when not evidently diseased, they should be removed at the sume time as the diseased mamma, or, in other words, "it is advisable to remove the axillary glands in all cases of cancer of the breast submitted to operation."

\section{ON THE}

CLAIM OF PROFESSOR BIZZOZERO TO THE DISCOVERY OF THE FIBRIN-FORMING CORPUSCLE OF THE BLOOD.

By RICHARD NoRRIS, M.D. St. ANd., F.R.S.E, PROFESSOR OF PHYSIOLOGY, QUEEN'S COLLEGE, BIRMINGHAM.

IN a leader in The LANCET of March 18th, reference is made to a communication by Professor Bizzozero, which appeared in the Centralblatt of March 11th, in reply to a letter of mine, published in THE LANCET of Jan. 28th. It seems to me that quite apart from all personal considerations, the question is one of such general and paramount interest in physiology and pathology, as to warrant me in returning to the subject, with a view to the more complete elucidation of its existing position. It is a well-known fact, of which I possess the fullest documentary evidence, that so early as February, 1878, I sought to secure to British physiology any credit which might accrue from the discovery of the fact that the existing chemical views of coagulation were destined to give place to morphological ones; in brief, that there existed in the blood a surpuscle the degenerative changes of which were competent to account for and explain all the phenomena of finriu formation. I have traced these corpuscles, step by step, throughout the whole of their changes and variations, and have photographed each successive divarication till they present themselves in the well-recognised forms of fibrin-e.g., films, networks, embolic masses, \&c. Now Professur Bizzozero clairus for the corpuscles which he has seen the same properties which long ago I ascertained to belong to my corpuscles, nevertheless he denies to me the disenvery of any new body, and contents himself by affirming that I have mistaken decolourised discs for a new element of the blood. Where is the logic of this? Will Professor Bizzozero maintain that having first deluded myself, I have next entered into all kinds of speculations relarive to the fibrin-forming power of this body, and that these speculations turn out so accurate as to render it simply necessary to discover the actual body to which they are related, and by a simple exchange at once to cornplete an important research, the final issues of which had been already worked out ; for there is no new fact in the original communication of Professor Bizzozero save that he has seen in the vessels of chloralised rodents a corpuscle with which he was not previously familiar? It seems to me that the only other alternatives open are either to admit that decolourised discs are the fibrin factors of the blood, or to affirm that he has also discovered in the blood another and an independent corpuscle which is capable of uudergoing the same series of changes as mine. Is not the suspicion, which has already occurred to Professor Bizzozero, that he has come across one of the many transition phases of the corpuscles which I have described much more probdble? I entirely concur with him when he says: "Above all, we must know if my blood-dises are identical with the corpuscles of Norris." Proceeding to contrast these corpuscles, he says: "The latter are, according to the deccription of Norris, of the same magnitude as the red discs, aud lose their former invisibility only in the measure that they become charged with hæmoglobin; on the other hand, my blood-discs have generally a diameter two or three times smaller than that of the red corpuscles, and are never coloured by hæmoglobin; they are visible because they are granular, and because they possess a power of refraction differing from that of the plasma of the blood, whilst those of Norris refract the light in the same way as the plavma, and become therefore visible only when they are slightly coloured." He proceeds, "Truly, Norris might try to defend the supposed identity of both elements on the supposition that the dises might be a transition product of his invisible corpuscles, yet I might easily disprove this supposition by showing that the discs are visible with their tyuical characteristics in their most normal condition in the living circulating blood itself." The description here given by Professor Bizzozero of the bodies he has observed is much more explicit than in his oriyinal communication, in which he said that the reason they had hitherto escaped notice was due to their being colourless and translucent, but he now adds that they are visible because they are granular, and because they possess a power of refraction differiug from that of the plasma of the blood. We have now to guide us in their identification five things: size, form, visibility, granular character, and absence of colour.

At this point it is desirable for me to state again my case, in a manner which does not seem to have presented itself to the mind of Professor Bizzozero. The question at issue is not whether the dises described by him are identical with my invisible corpuscles, but rather whether they belong to that series of dises which, on account of their tendency to degenerate into fibrin, I have desigaated the "fugitive group," some of the corpuscles of which are visible, others barely visible, and others still wholly invisible. At both ends of this group there are visible dises, for it includes on the one hand the advanced or nuclear lymph-discs, which are antecedent to the iuvisible dises, and on the other those dises which have again become visible by the acquisition of colour, but which are not yet sufficiently stable to be included in the permanent group of red discs. These limitations I have repeatedly stated in my papers. According to my view, therefore, all the younger discs of the blood, some of which are colourless and yet visible (like the white corpuscles but more delicate), others of which are colourless and invisible, and others partly coloured, and therefore visible, undergo conversion into fibrin when the blood is shed. Professor Hayem is well acquainted with the fact that bodies containing 